\title{
Assesment of Renewable Energy Sector in Pakistan
}

\author{
Adan Zahid ${ }^{1}$, Tayyaba Sony ${ }^{2}$, Shehla Noor ${ }^{13}$ \\ ${ }^{1,2,3}$ USPCAS E UET Peshawar \\ azahid2@asu.edu ${ }^{1}$ \\ Received: 06 November, Revised: 17 Novemeber, Accepted: 20 November
}

\begin{abstract}
With the increasing technological advances, the global energy needs are increasing exponentially. The ever increasing demand of electricity has compelled generation sector to highly depend on fossil based fuel but the irony is that the fossil fuel is not only costly but also pose hazard to environment. Therefore, shift towards Renewable Energy (RE) is vital for every country. Currently, RE sector in Pakistan is underdeveloped though some projects have been initiated in Pakistan to decrease reliance on fossil fuel and to lessen the energy shortage in Pakistan. Globally, many countries like Germany and China are heavily investing in renewable energy. Hence, it is important to know the status of renewable energy project growth in Pakistan in comparison to other countries. The proposed methodology aims to find the growth of RE in Pakistan energy mix in comparison to bench mark country as China, Germany, India and Saudi Arabia. This is done to understand the current progress of Pakistan in expanding RE projects, against certain developed and under developed counties. For this study, solar, wind and small micro hydro sectors of Pakistan has been considered. After analysis, the challenges and way forward for successful integration of RE in Pakistan is put forth by this study.. The results of this study will help the policy makers of Pakistan in choosing the right energy resource which is not only cost effective but also environmental friendly. This will help Pakistan in ensuring economic energy projects along with mitigation of greenhouse emissions.
\end{abstract}

Keywords - Renewable Energy, LEAP

\section{INTRODUCTION}

With the dawn of new millennium, the Renewable resources (RE) has captured the attention of policy makers and researchers due to exponential rise of energy demand and loaming threats of global warming. In case of Pakistan, the gap between electricity demand and supply plummeted to 5201 MW which resulted in load shedding of 14-18 h daily [1]. During ,1980, in Pakistan the total share of hydro power in energy mix was almost $70 \%$ [1]. According to the same study, due to political instability of 1990's, every elected government adhered to short term electricity projects that relied on extravagant oil import which resulted in reduction of the hydropower share to $31 \%$. In recent years, the public and government sensitivities towards environmental issues has resulted in incorporation of RE into Pakistan energy mix. But the total exploitable RE potential of Pakistan is greater than the total percentage of RE in energy mix. On the contrary, many countries around the globe has made significant success in terms of augmenting share of RE in energy mix one such as Germany and China. Therefore, it is important to make an analysis of growth trend of RE in Pakistan against certain bench mark countries. This thesis deals in comparing the growth of $\mathrm{RE}$ in Pakistan against Developed and Developing countries. For this scenario, Germany is taken as a case study from developed nation whereas China and India cases have been taken from category of developing nation. Moreover, one OPEC country i.e. Saudi Arabia will be also taken into consideration in order to compare the status of renewable in Saudi Arabia vs. Pakistan.

Furthermore, to enhance the share of RE in Pakistan energy mix and to know its impact on economy and environment; it is essential to model the current energy generation sector of Pakistan. Most of developed countries rely heavily on results of energy models for their future energy policies. Hence the need of the hour is that the policy makers of Pakistan should take into account the results of energy models for formulating future energy policy. The result of energy models predicts cost effective and environmental friendly resources for Pakistan's energy mix.

\section{BACKGROUND}

Energy related challenges are among the greatest world has to endure in the coming years. This and with an ever increasing population of over 200 millions), the shift to renewable energy becomes even more important. Moreover, a growing gap between energy demands and supply in Pakistan, has is because economic competitiveness of emerging economies is highly dependent on reliable energy resource availability. If proper support is provided, renewable energy technologies can satisfactorily meet much of the growing demand at prices less than those usually forecasted for conventional energy [1,2]. Therefore, for countries like Pakistan (blessed with natural resources further increased threat to our long-term survivability and existence as a just nation. Although many renewable energy projects have been initiated by Pakistan over past decade especially in micro hydel, wind and solar sector yet the growth of 
renewable sector is not heartening if we compare growth trend of renewable with other countries. There is a need to analyze previous installed projects in order to assess their efficiency and growth. Moreover, to calculate the impact of RE integration in Pakistan energy mix a full-fledged energy modeling is necessary. The result of such a simulation can help policy maker to put forward a future energy policy.

\section{A. Conventional Energy Resources in Pakistan}

\section{Oil}

Pakistan utilizes $25 \%$ of its total oil import in energy sector, during 1990's and by 2015, 45\% of oil import is consumed by electricity sector [4]. According to the study mentioned, when oil price surged from $25 \$$ /barrel to 50\$/barrel from 2001 to 2005; government decided to diversify its energy mix. Hence, shift to other resources was made.

\subsubsection{Hydroelectric power}

The Two break through projects that gave impetus to hydroelectric power in Pakistan energy mix are: Mangla dam and Tarbela. These were completed between 1967 and 1976, respectively, after Pakistan became signatory of Indus water Treaty [3]. Today, the net installed capacity of hydroelectric power in Pakistan is approximately $7116 \mathrm{MW}$, which accounts for $17 \%$ of total hydroelectric potential which stands at 41,700 MW[3].

\subsubsection{Coal}

According to several surveys, the total coal reserves of Pakistan are approximately 186 billion tones [2]. Despite of such a huge reserves the share of coal in energy mix is meager. It remained at less than $1 \%$ in the power sector during 2014 [2].

\subsubsection{Natural gas}

The total resource potential of natural gas in Pakistan is approximately 282 trillion cubic feet [2]. According to same study the country produces approximately 4 billion cubic feet per day which places Pakistan among large consumers of the natural gas.

\subsubsection{Nuclear energy:}

Pakistan Atomic Energy Commission (PAEC) is the government institution which is primarily assigned with the task of planning and management of national nuclear plants. Currently, the nuclear power plants in Pakistan account for 5\% of total electricity generation in Pakistan [2] . According to study [2] Pakistan Atomic Energy Commission (PAEC) is now aiming for the installation of over $8000 \mathrm{MW}$ nuclear power capacities by the year 2030. Apart from conventional energy resources, Pakistan is striving to make renewable apart of its energy mix.
The government of Pakistan has strived to avail the Solar, Micro Hydro and Nuclear Energy Resources:Since, this study will compare the growth of renewable sector of Pakistan against China, India, Germany and Saudi Arabia; it is essential to have a look at the status of renewable in these countries. Renewable energy status in Pakistan:

\section{B. Renewable Energy Status In Pakistan}

Pakistan is among SAARC nations, located in South Asia. It is energy deficient since it lacks hydro carbons and hence it has to make its need by importing hydrocarbons [4]. The import of hydrocarbons makes up $20 \%$ of entire annual import bill [5]. According to study [6] Pakistan has the potential to generate at least 167.7 GW. The terrain of Pakistan receives approximately $15.5 \times 1,014 \mathrm{kWh}$ solar radiation [7]. This shows Pakistan has high potential to exploit solar energy to make electricity since in most part of the country the effective sun shines hours are approximately eight to nine hours/day [7] . Recently, Pakistan seems keen is utilizing more of solar energy. For instance, Pakistan engineering council (PEC) commissioned first on grid power plant in 2010 [7]. The power plant has facility of net metering to IESCO. Moreover, The Parliament of Pakistan has been fully powered with solar energy. The success of these projects encouraged other investors to extend investment in renewable energy sector. These solar based renewable energy projects are in different developmental stages. Further, 7 IPPs have obtained letter of support from AEDP for a total of 72.23 MW [8]. As per study [9] poor policy and lack of technology is a constraint that solar industry faces in Pakistan

Government of Pakistan has also made some progress in harvesting potential of wind energy. Pakistan meteorological department has conducted a thorough survey about Pakistan's wind potential. The study shows Sindh has more potential in terms of wind energy than coastal areas. Almost 9700 sq.km has potential to make electricity from wind. If area's utilization constraints are kept in view, still $43000 \mathrm{MW}$ appears to be gross power potential whereas studies show that almost $11000 \mathrm{MW}$, can be exploited from this coastal belt [10]. Similarly, the survey from meteorological department has depicted low wind potential in Northern area of Pakistan [11]. The first wind project was installed by renowned Fauji Fertilizer in early 2013 with total installed capacity of $50 \mathrm{MW}$ [11]. Later on 6 more such a projects have been initiated in coastal areas of Sindh [11].

A far as small micro hydro is concerned; Pakistan has good potential in micro hydro in Northern areas. Government hands also taken initiative to exploit hydel potential. different micro hydro projects are under developmental stages whose aggregate capacity is $2638 \mathrm{MW}$ [12].

\subsection{Status of renewable energy in China}

China has heavy demand of energy for its expanding economy. but the lack of hydro carbons has pushed China to explore renewable energy resources. The government China has set a 
target of increasing share of renewables in its energy mix and reach milestone of $15.4 \%$ by 2010 [13]. In 2010 China excelled USA in wind energy production by 2010 [14]. Since 2000, the installed capacity of wind energy in Chinese energy mix has augmented exponentially, from 300MW to 42,287 MW [14]. Among total wind energy of the world which is 194,390 MW, China makes $21.8 \%$ [14].As far as wind sector in China is concerned, stress on wind energy started in 1994, when government enunciated regulations to encourage wind energy exploration. These regulations resulted in production of 224 MW in late 1998 [15]. The study [16] has concluded that by 2007 the net installed capacity of wind in China crossed 5900 MW. This drastic increase was made possible by the high wind potential onshore regions of China. The offshore Chinese regions displayed comparatively low progress. According to the aforementioned study china is aiming to have an installed capacity of $30 \mathrm{GW}$ by 2020 [16] .

The Chinese land stretches a good 9.6 Mn km-sq land. It is also included among solar belt countries [14]. The study [17] gives an overview of growth of solar energy in China in past years. As per CSP, a region with DNI level above $1800 \mathrm{KWh}$ produces economic energy. According to aforementioned study, the northern and western terrain of PRC meets this criterion. The installed solar energy capacity in China in 2004 was approximately $0.06 \mathrm{MW}$. As per the same study, the government is aiming to achieve a milestone of $1.8 \mathrm{GW}$ in solar energy.

\subsection{Status of Renewable Energy in India}

India is industrializing at a rapid pace. Like china, India is also deficient in hydrocarbons. India is blessed with a geography and climate weather that enables it to exploit wind energy. In India, the summer and winter monsoons ensure effective wind speed to run turbine and generate wind energy [13]. As per The Indian Renewable Energy Development Agency (IREDA), the wind potential of India is approximately 45,195 MW. But due to certain constraints, $12000 \mathrm{MW}$ can be utilized. The study (Sharma et al, 2012) reveals that over the time, wind generation has grown and the cost has been brought down. The cost per $\mathrm{kW}$ t ranges from $\$ 1413.8 / \mathrm{kW}$ to $\$ 1908.6 / \mathrm{kW}$ (Sharma et al, 2012). This growth in wind energy can be attributed to Government policy which ensures incentive, income tax holidays and other subsidies to those investors who are investing in this sector [36]. India has a good potential to explore solar energy since it has good DNI [18]. According to study aforementioned study, the 5000 trillion $\mathrm{kWh}$ per year is the estimated potential for solar energy. During 2014, the installed solar capacity in India is estimated to be $2.2 \mathrm{GW}$ according to the same study. The solar energy couldn't grow the way wind energy was integrated in India. Several reasons have been enlisted by the aforementioned study such lack of availability of reliable data, lack of technology and proper infrastructure. According to the Institute of Energy Economics and Financial Analysis Wholesale price of small micro hydro, wind and solar INR/KWh is $3.5,4.5$ and 5.6 respectively [18] which are higher than price of domestic coal and nuclear power plant. According to study [19], the installed capacity of small micro hydro in India by 2006 was $1800 \mathrm{MW}$. The growth rate according to same study for small micro hydro over year 2000 to 2006 is approximately $6 \%$ which is pretty small than that of wind is $40 \%$.

\subsection{Status of Renewable Energy in Saudi Arabia}

Saudi Arabia is rich in hydrocarbons but constant use of fossil based fuel Saudi Arabia in late $20^{\text {th }}$ century has led to depletion of the hydro carbons. Saudi Arabia is equally blessed with a terrain that receive an average $2200 \mathrm{kWh} / \mathrm{m} 2$ of solar radiation annually [8]. But less importance has been given to renewable energy in Saudi's energy policy due to a prevailing perception that solar energy has negligible importance in industrial development of the country. According to the same study, the first use of solar energy application commenced in 1960's. Later on, in 1980's; Saudi kingdom collaborated with Germany. In 2010, the Saudi Aramco took the project of constructing 10 MW solar power plant [8].

\subsection{Status of Renewable Energy in Germany}

Efforts are being made globally to explore renewable energy resources to limit the increasing carbon dioxide content in atmosphere and to minimize the increasing cost of fossil based fuels around globe, especially after the oil crisis of 1979. For electricity generation, wind energy is considered one of the best choices in world. Several researches have been undertaken to make wind energy cost effective and efficient energy resource. Different studies have been conducted in past to know the wind energy potential across the Europe. Hence, a total of $56 \mathrm{GW}$ wind potential has been achieved in Europe. Over the past few years, Germany has increased seen major growth in share of renewable energy in its energy mix. Renewable energy increase in 2009 is almost triple the value of 1998. In 1998, the share of renewable energy was mere 3.6, which reached to a high value of $8.4 \%$ [20]. According to the same study, the highest growth was seen in wind energy sector. During 2009 the According to the study the success of renewable energy in Germany can be attributed to legislative measures by the government. In 2008, the new initiated setups were using renewable (8.5 GW) [20].

\section{Comparative analysis of growth of RE across the World}

The purpose of this study is making a comparative analysis of the growth trend of renewable in Pakistan against certain bench mark countries. For this reason, let's have a look at different comparative analysis of renewable growth performed by various researchers.

The study [21] has made a comparative analysis of shift towards renewable energy in developed and under developing countries. For this reason, data is collected from various data banks such as World Bank, Factbook etc. For case study of developed country, USA is considered whereas Kenya and Morocco has been assumed from category of developing nation. The current growth and future trend has been discussed by making projection till 2040. Based on energy demand till 2040, a 
blueprint for $100 \%$ integration of renewable energy as a case study has been produced. Though, an ideal situation of $100 \%$ renewable energy integration has been produced by study [21], it provides useful information in step wise phasing out dependence of a country on non-renewable energy resources.

Another study [22] has solely stressed on comparative analysis of determinants that are responsible for renewable energy sector of China and India. The basis for this study was that similar challenges faced by two countries in term of population, greenhouse emissions (GHE's), greater energy needs for expanding economies. The researchers; to find linkages between renewable energy growths, carbon dioxide emission, have used the multivariate vector error correction model (VECM). The causality found between outputs in case of China is one-directional but bidirectional in case of India. This result points towards inherent interdependency of GHE's, growth and energy production.

Similarly, another comparative analysis of renewable sector of across Europe is undertaken by study [23]. This time causal relationship between economic growth and renewable has been taken under consideration. The researcher has used data for 27 countries, comprising of real GDP of people, percentage of RE in energy consumption and GHE emission. Various component models are used to analyze the data. This study reveals a weak relation between economic growth and renewable energy consumption. Researcher through neutrality principle explains this result.

In another paper [24], a brief review on the supporting policies adopted for Renewable energy resources in Europe has been conducted. For this purpose, a case study of four countries: France, Germany, Italy and Spain is considered. The purpose of this study is to highlight the main differences in the support policies adopted for Photovoltaic (PV) and Wind systems. The supporting policies assumed in this study are: Green tags (GT), Net-metering and Feed-in tariff (FIT).

The aim of paper [25] is to analyze the development status of PV system of some European Union (EU) countries. These countries include France, Germany, Greece, Italy and the U.K. The convenience of several support policies for PV has been evaluated by keeping in view the specific situation of these five member states. The net present value (NPV) and the internal rate of return (IRR) have been chosen in this comparative study as economic indexes. This study is particularly helpful in assessing the impacts of energy policy in selected E.U. members, in what manner PV market will grow in near future and which policy is beneficial for future PV sector of these countries.

\section{COMPARATIVE ANALYSIS}

\section{A. Case Study of Pakistan vs Developing Cuntries with similar Geagraphic and Econmic Condition}

The figure 6 depicts share of renewable energy in Pakistan and India energy mix. The portion of renewable energy in India is far greater than that of Pakistan but this can be attributed to the $6^{\text {th }}$ times more population and hence greater energy needs of
India. But figure 20 shows the percentage increase of renewable energy in Pakistan occurred at faster pace than India. If we break down different sectors of renewable energy in India and Pakistan and further compare their performance; observe that the wind sector of India is doing better than that of Pakistan. This can be attributed to the fact that India enjoy comparatively more coastal belt, almost 7,516.6 km compare to Pakistan which has $1050 \mathrm{~km}$ of coastline. Similarly, India has shown remarkable progress in PV solar energy after 2016.

In case of small micro hydro, Pakistan's generation capacity is almost similar to that of India. Keeping in view the 6 times more population of India, these results depicts Pakistan is doing well in micro hydro.

To conclude, Pakistan can look up to the PV and wind sector of India for improvement in its renewable energy in total energy mix. This is because India and Pakistan lies is South Asia, both are neighbors and listed among developing nations. Hence it will be easy for Pakistan to look up to PV and wind sector of India and implement it in Pakistan.

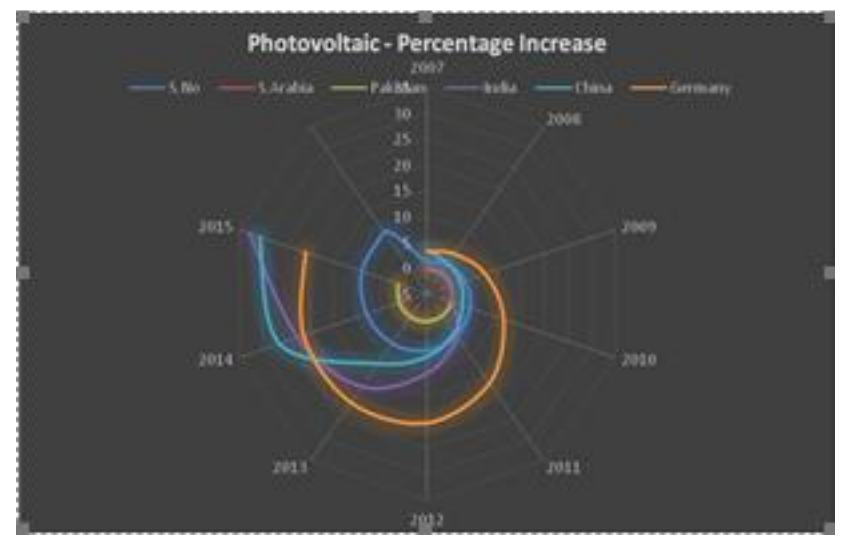

Figure III-1 Caparison of Solar Energy Resource of Pakistan vs other Countries

\section{B. Case study of Pakistan vs. Developed nation (China)}

The figure III-I depicts share of renewable energy in Pakistan and China energy mix. The portion of renewable energy in China is greater than that of Pakistan. This can be attributed to the fact that China is 7 times more populous than Pakistan and is going through industrialization. Hence energy needs of China are greater. But figure III-2 shows the percentage increase of renewable energy in Pakistan occurred at faster pace than China. If we break down different sectors of renewable energy further in China and Pakistan, we observe that the growth sector of wind sector in China and Pakistan is almost same in 2009. But by 2019 the growth rate of China is better than Pakistan. Similarly, China has excelled Pakistan in solar and micro hydro sector as well. This fact can be attributed to the fact that China enjoys superior technological advancement accompanied by trained work force as compare to Pakistan. 


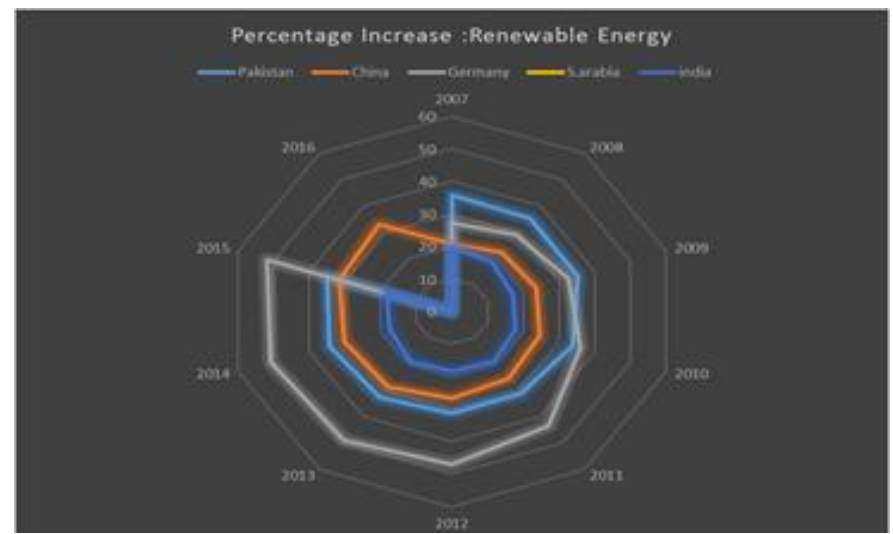

Figure III-2 Percentage Increase in Renewable Energy

\section{Case study of Pakistan vs. Developed nation (Germany)}

Germany is a developed nation like China. The comparison of renewable energy sector of Germany in contrast to Pakistan is almost similar to that of China. This can be attributed to the availability of state of art technology of renewable resources exploitation in Germany. Moreover, the RE friendly national policies adopted in Germany has also helped in vigorous developed RE sector of Germany.

Last but not the least, the energy demand of Pakistan will soar in upcoming years hence it is necessary to implement an effective RE policy based on above recommendations and simulation.

The preferred spelling of the word "acknowledgment" in America is without an "e" after the "g". Avoid the stilted expression, "One of us (R. B. G.) thanks ..." Instead, try "R. B. G. thanks".

\section{CONCUSLION}

Countries all over the globe are making shift to renewable energy due to limited hydro carbon. Though many RE projects are installed in Pakistan, it is important to know the growth RE in Pakistan energy mix with respect to other countries. This will help Policy makers of Pakistan to implement identify any loopholes and make amendments in future energy policy for successful integration of RE in Pakistan energy mix. Pakistan $\mathrm{RE}$ sector development pace is relatively slow as compare to the bench mark countries. This study also reveal that huge potential exist in Pakistan to make RE projects sustainable. In this milieu, the Indian RE sector can be looked up by the policy makers of Pakistan due the fact that India is Pakistan's neighbor and both countries has similar social, economic and technologically advanced. Moreover, the both countries have almost similar terrain condition. Another prospect for Pakistan energy sector is that China is investing in energy projects under CPEC. Pakistan can immensely benefit from Chinese technology, since China is leading in Renewable resources in world. Chinese cooperation can enable Pakistan to produce RE equipment indigenously. Furthermore, the simulation results show that solar and coal energy of Pakistan should be utilized since both ensure comparatively cheaper electricity. On the other hand, wind energy proves to be more expensive option in terms of RE utilization since it has high investment cost. This is evident from the result of cost of production and Investment cost results. If we analyze the result of carbon emission, the Coal and biomass scenario gives more carbon emissions as compare to wind and solar. Hence, it can be concluded that if tradeoff between Cost and Carbon emission has to be made than Biomass Scenario suits Pakistan. This will help Pakistan in mitigating the loaming environmental challenges along. Similarly, solar can ensure comparatively cheaper energy which can be translated into economic boom for Pakistan since the end product of any industry depends on the cost of energy.

\section{REFERENCES}

[1] M. Kamran, "Current status and future success of renewable energy in Pakistan," Renewable and Sustainable Energy Reviews, vol. 82. Elsevier Ltd, pp. 609-617, 2018

[2] G. Das, M. Aslam, H. Rahman, R. Samoo, N. Hussain, and K. Harijan, "Overcoming electricity crisis in Pakistan: A review of sustainable electricity options," Renew. Sustain. Energy Rev., vol. 72, no. January, pp. 734-745, 2017.

[3] O. Rauf, S. Wang, P. Yuan, and J. Tan, "An overview of energy status and development in Pakistan," Renewable and Sustainable Energy Reviews. 2015.

[4] S. A. Ur Rehman, Y. Cai, N. H. Mirjat, G. Das Walasai, I. A. Shah, and S. Ali, "The future of sustainable energy production in Pakistan: A system dynamics-based approach for estimating hubbert peaks," Energies, vol. 10, no. $11,2017$.

[5] M. Ragazzi, M. Maniscalco, V. Torretta, N. Ferronato, and E. C. Rada, "Anaerobic digestion as sustainable source of energy: A dynamic approach for improving the recovery of organic waste," Energy Procedia, vol. 119, pp. 602-614, 2017.

[6] M. K. Farooq and S. Kumar, "An assessment of renewable energy potential for electricity generation in Pakistan," Renew. Sustain. Energy Rev., vol. 20, pp. 240-254, 2013.

[7] M. S. Malkani, A review of coal and water resources of Pakistan, vol. 31. 2012.

[8] A. Hepbasli and Z. Alsuhaibani, "A key review on present status and future directions of solar energy studies and applications in Saudi Arabia," Renew. Sustain. Energy Rev., vol. 15, no. 9, pp. 5021-5050, 2011.

[9] U. K. Mirza, M. Mercedes Maroto-Valer, and N. Ahmad, "Status and outlook of solar energy use in Pakistan," Renew. Sustain. Energy Rev., vol. 7, no. 6, pp. 501-514, 2003.

[10] J. C. Godenzzi, “No 主観的健康感を中心とした在宅高齢者における 健康関連指標に関する共分散構造分析 Title,” vol. XX, no. 1990, pp. 317-331, 1996.

[11] "Pakistan Meteorological department." [Online]. Available: http://www.pmd.gov.pk/wind/Wind_Project_files/Page767.html.

[12] M. Kamran, "Current status and future success of renewable energy in Pakistan," Renew. Sustain. Energy Rev., vol. 82, no. September 2017, pp. 609-617, 2018.

[13] M. Carolin Mabel and E. Fernandez, "Growth and future trends of wind energy in India,” Renew. Sustain. Energy Rev., vol. 12, no. 6, pp. 17451757, 2008.

[14] X. Changliang and S. Zhanfeng, "Wind energy in China: Current scenario and future perspectives," Renew. Sustain. Energy Rev., vol. 13, no. 8, pp. 1966-1974, 2009.

[15] C. W. E. Association., "Status and development of China wind industry," 2006. [Online]. Available: http://www.crein.org.cn.

[16] David K., "A method for developing geographic-economic wind supply curves: China case study." 2008.

[17] Q. Hang, Z. Jun, Y. Xiao, and C. Junkui, "Prospect of concentrating solar power in China - the sustainable future," 2008.

[18] K. Kapoor, K. K. Pandey, A. K. Jain, and A. Nandan, "Evolution of solar energy in India: A review," Renew. Sustain. Energy Rev., vol. 40, pp. 475-487, 2014.

[19] I. R. Pillai and R. Banerjee, "Renewable energy in India: Status and potential," Energy, vol. 34, no. 8, pp. 970-980, 2009. 
[20] R. Hinrichs-Rahlwes, "Renewable energy: Paving the way towards sustainable energy security. Lessons learnt from Germany," Renew. Energy, vol. 49, pp. 10-14, 2013.

[21] N. Vandaele and W. Porter, "Renewable Energy in Developing and Developed Nations : Outlooks to 2040," vol. 15, no. 3, pp. 1-7, 2015.

[22] S. Rafiq, H. Bloch, and R. Salim, "Determinants of renewable energy adoption in China and India: a comparative analysis Determinants of renewable energy adoption in China and India : a comparative analysis," no. July, pp. 37-41, 2014

[23] A. N. Menegaki, "Growth and renewable energy in Europe : A random effect model with evidence for neutrality hypothesis," Energy Econ., vol. 33, no. 2, pp. 257-263, 2011.

[24] N. Park, S. Yun, and E. Jeon, “An analysis of long-term scenarios for the transition to renewable energy in the Korean electricity sector," Energy Policy, vol. 52, pp. 288-296, 2013.

[25] L. Dusonchet and E. Telaretti, "Comparative economic analysis of support policies for solar PV in the most representative EU countries," Renew. Sustain. Energy Rev., vol. 42, pp. 986-998, 2015. 